\title{
In-vitro maturation and penetration of mouse primary oocytes after removal of the zona pellucida
}

\author{
Z. Binor and D. P. Wolf \\ Division of Reproductive Biology, Department of Obstetrics and Gynecology, University of \\ Pennsylvania School of Medicine, Philadelphia, Pennsylvania 19104, U.S.A.
}

\begin{abstract}
Summary. The spontaneous maturation of intact, cumulus-free and zona-free oocytes of the mouse was studied in complex and in simple media. The rates and frequencies of maturation from the germinal vesicle to the metaphase II stage were similar for all oocytes, indicating that these investments are not critical to maturation. The penetration characteristics of zona-free oocytes were examined; before germinal vesicle breakdown (GVB), evidence for penetration was obtained only when the ionophore, A23187, was included in the medium. After GVB, oocytes readily incorporated spermatozoa and were usually polyspermic when inseminated with $10^{3}$ capacitated epididymal spermatozoa $/ \mathrm{ml}$. The kinetics of sperm incorporation indicated that primary oocytes were capable of a plasmalemma block to penetration similar to that seen with tubal eggs.
\end{abstract}

\section{Introduction}

Before ovulation, mammalian oocytes are arrested in the prophase stage of meiosis, and the resumption of this process is triggered in a limited number of primary oocytes in each ovarian cycle by the gonadotrophin surge. The first morphological indicator of resumption is the disintegration of the nuclear membrane (germinal vesicle breakdown, GVB), which is followed by condensation of the diffuse dictyate chromatin into distinct bivalents, separation of homologous chromosomes, eventual cytoplasmic division and extrusion of the first polar body, thus producing a secondary oocyte. Upon release of dictyate stage oocytes into a suitable culture medium, a spontaneous resumption of maturation occurs in all mammalian species studied (reviewed by Thibault, 1977). In the mouse, preovulatory maturation in vitro requires $12-15 \mathrm{~h}$ and leads to the production of fertilizable eggs, some of which will develop normally to term (Cross \& Brinster, 1970; Mukherjee \& Cohen, 1970). The role of culture media and cumulus cells in spontaneous maturation of zona-intact mouse oocytes has been studied extensively; a relatively simple chemically defined medium will suffice and the presence of cumulus cells, while supportive, is not essential for oocyte maturation (Biggers, Whittingham \& Donahue, 1967; Donahue \& Stern, 1968; Cross \& Brinster, 1970). In contrast, the role of the zona pellucida in the maturation process has not been evaluated.

The penetration characteristics of oocytes matured in vivo and in vitro have been examined in several species; after GVB, oocytes are capable of incorporating spermatozoa (Iwamatsu \& Chang, 1972; Barros \& Munoz, 1973). Transmission electron microscopic (TEM) studies of zona-free hamster oocytes indicate that sperm incorporation may occur before GVB but without subsequent decondensation of the sperm head in the egg cytoplasm (Usui \& Yanagimachi, 1976).

In the present study, we examined the role of the zona pellucida in the spontaneous maturation of mouse oocytes and the ability of zona-free, immature oocytes to incorporate spermatozoa. 


\section{Materials and Methods}

Follicular oocytes were obtained from ovaries of 8-10-week-old Swiss mice chosen at random. Animals were killed by cervical dislocation, and dissected ovaries were freed of adipose tissue and placed in Petri dishes containing isotonic $\mathrm{NaCl}(0.9 \% \mathrm{w} / \mathrm{v})$. This and all subsequent steps were conducted at $37^{\circ} \mathrm{C}$. Ovaries were transferred to a depression slide containing $1 \mathrm{ml}$ culture medium, and oocytes were liberated by puncturing follicles with a 27 -gauge hypodermic needle. Typically, 15 oocytes were recovered per ovary. Two kinds of media were used; (1) a complex medium consisting of TCM 199 with Hank's base modified by the addition of 0.5 mM-sodium pyruvate and $15 \%$ calf serum (Cross \& Brinster, 1970), and (2) the simple modified KrebsRinger medium described by Biggers (1971).

Three groups of oocytes at the dictyate stage (GV-intact) were studied: (A) oocytes released from their follicles without additional manipulation, i.e. with adherent cumulus cells; (B) oocytes whose cumulus cells were subsequently removed by repeated micropipetting; (C) oocytes whose zonae were removed enzymically $(0.5 \% \alpha$-chymotrypsin for $1-2 \mathrm{~min})$.

Oocytes were cultured in $0.2 \mathrm{ml}$ drops of medium under silicone oil (Dow-Corning 200 fluid) in $5 \% \mathrm{CO}_{2}$ in air. For scoring nuclear maturation or sperm penetration, oocytes were mounted, fixed, stained with aceto-lacmoid and examined with a phase-contrast microscope. The stages of nuclear maturation were classified according to the criteria of Donahue (1968).

Zona-free oocytes were exposed, under the following conditions, to epididymal spermatozoa (approximately $10^{5} / \mathrm{ml}$ ) which had been capacitated by a 1-h preincubation in Toyoda's medium (Wolf \& Inoue, 1976). (1) Maturing oocytes: oocytes recovered at various phases of maturation were inseminated for $3 \mathrm{~h}$ in Medium 2. (2) Mature tubal oocytes served as controls. These eggs were recovered in Medium 2 from oviducts of superovulating animals, 14-15 h after hCG injection, and were treated with hyaluronidase $(1 \mathrm{mg} / \mathrm{ml})$, before zona removal and incubation with capacitated spermatozoa for $3 \mathrm{~h}$. (3) Dibutyryl cyclic AMP-arrested oocytes. To prolong the contact time between spermatozoa and GV-intact oocytes, inseminations were also conducted for 6 and $9 \mathrm{~h}$ in Medium 2 containing $100 \mu \mathrm{g}$ dibutyryl cyclic AMP/ml (Cho, Stern \& Biggers, 1974). (4) Ionophore-treated oocytes. The oocytes were inseminated with ionophore A23187 (11 $\mu \mathrm{g} / \mathrm{ml}$ )-pretreated spermatozoa in the presence of ionophore. Incubations were conducted for $3 \mathrm{~h}$ in Medium 2 with or without dibutyryl cyclic AMP. Ionophore was obtained from Dr Robert Hammill (Eli Lilly Co., Indianapolis, Indiana) and stored in the dark at $-20^{\circ} \mathrm{C}$ in stock solutions $(1.1 \mathrm{mg} / \mathrm{ml}$ in dimethylformamide).

In all the above experiments, inseminated oocytes were fixed, stained with aceto-lacmoid, scored for sperm penetration and stage of nuclear maturation. Evidence of penetration included sperm head remnants and a sperm tail within the egg cytoplasm. For TEM examination, oocytes

\section{PLATE 1}

Fig. 1. Zona-free oocyte with germinal vesicle intact.

Figs 2-4. Zona-free oocytes matured in vitro at the pro-metaphase I stage (Fig. 2), metaphase I stage (Fig. 3) and metaphase II stage with first polar body detached during fixation (pb) (Fig. 4).

Fig. 5. Light micrograph of a zona-free oocyte at the pro-metaphase I stage of meiosis and penetrated by at least four spermatozoa. Note the characteristic inner acrosomal membrane remnants (arrows) associated with each penetrating sperm tail. $\times 1600$; inset, $\times 2560$.

Fig. 6. Light micrograph of a GV-intact oocyte inseminated with capacitated epididymal sperm in the presence of ionophore A23187. Remnants of inner acrosomal membranes are clearly visible in the oocyte cytoplasm in close association with sperm heads (arrows). The dense circular nucleolus is visible within the germinal vesicle. $\times 2560$. 
PLATE 1
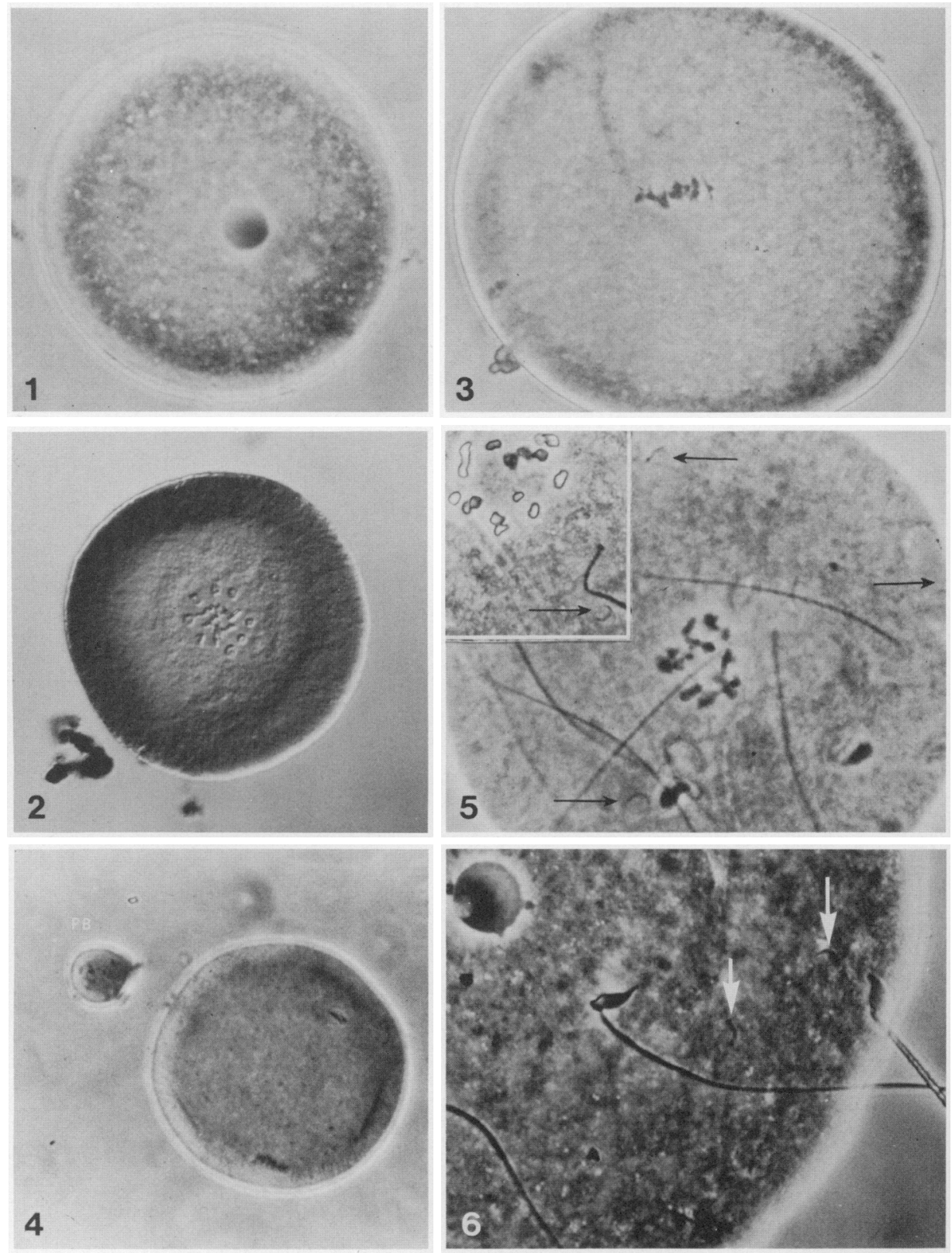

(Facing p. 310) 


\section{PLATE 2}
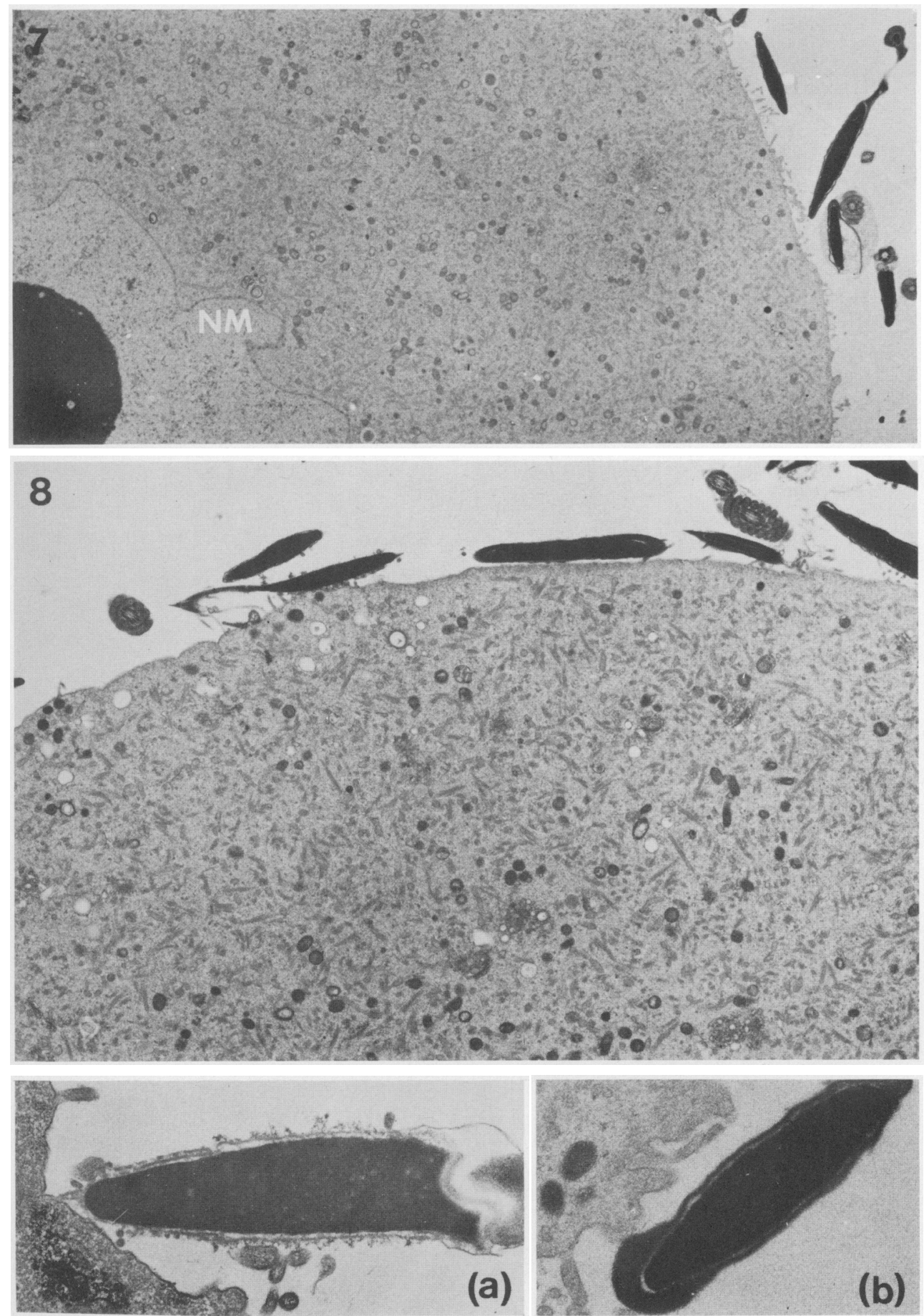
were fixed for $30 \mathrm{~min}\left(4^{\circ} \mathrm{C}\right)$ in $2.5 \%$ glutaraldehyde in $0.15 \mathrm{M}$-cacodylate buffer, rinsed, postfixed for $1 \mathrm{~h}\left(4^{\circ} \mathrm{C}\right)$ in $0.1 \%$ osmium tetroxide in $0.15 \mathrm{M}$-cacodylate buffer dehydrated through a graded series of ethanol and embedded in Epon 812 (Luft, 1961). Thin sections were stained with uranyl acetate and lead citrate (Reynolds, 1963) and examined with a Hitachi HU12-A electron microscope operated at $75 \mathrm{kV}$.

\section{Maturation in vitro}

\section{Results}

The maturation of oocytes proceeded at a comparable rate when simple (Medium 2) and complex (Medium 1) media were employed, and both the frequency and the rate of progression from GV-intact to metaphase II stages were similar for the three oocyte types examined (Table 1) (Pl. 1, Figs 1-4). A total of 589 oocytes in 6 separate experiments was employed: 185 cumulus-intact, 208 cumulus-free zona-intact, and 196 zona-free.

Table 1. Maturation kinetics (expressed as \%) of mouse ovarian oocytes in vitro in simple and complex media

\begin{tabular}{|c|c|c|c|c|c|c|c|}
\hline \multirow[b]{3}{*}{ Oocyte morphology } & \multirow{3}{*}{$\begin{array}{l}\text { Stage of } \\
\text { maturation }\end{array}$} & \multicolumn{3}{|c|}{ Medium 1} & \multicolumn{3}{|c|}{ Medium 2} \\
\hline & & \multicolumn{3}{|c|}{ Incubation time $(\mathrm{h})$} & \multicolumn{3}{|c|}{ Incubation time (h) } \\
\hline & & $4-5$ & $8-10$ & $14-15$ & $4-5$ & $8-10$ & $14-15$ \\
\hline \multirow{4}{*}{$\begin{array}{l}\text { Cumulus-intact } \\
\text { follicular oocyte }\end{array}$} & GV & 26 & 23 & 24 & 31 & 19 & 14 \\
\hline & Pro-met. I & 52 & 15 & - & 69 & 29 & - \\
\hline & Met. I & 22 & 39 & - & - & 52 & - \\
\hline & Met. II & - & 23 & 76 & - & - & 86 \\
\hline \multirow{4}{*}{$\begin{array}{l}\text { Cumulus-free zona-intact } \\
\text { follicular oocyte }\end{array}$} & GV & 25 & 26 & 23 & 25 & 17 & 15 \\
\hline & Pro-met. I & 55 & 15 & - & 75 & 28 & - \\
\hline & Met. I & 20 & 37 & - & - & 55 & - \\
\hline & Met. II & - & 22 & 77 & - & - & 85 \\
\hline \multirow{4}{*}{$\begin{array}{l}\text { Cumulus-free zona-free } \\
\text { follicular oocyte }\end{array}$} & GV & 25 & 18 & 21 & 29 & 21 & 19 \\
\hline & Pro-met. I & 50 & 16 & - & 71 & 31 & - \\
\hline & Met. I & 25 & 39 & - & - & 48 & - \\
\hline & Met. II & - & 27 & 79 & - & - & 81 \\
\hline
\end{tabular}

GV, germinal vesicle; Pro-met. I, pro-metaphase I; Met. I, metaphase I; Met. II, metaphase II.

\section{Insemination of zona-free oocytes}

Light microscopic examination of GV-intact zona-free oocytes (47) incubated for $3 \mathrm{~h}$ with capacitated epididymal spermatozoa provided no evidence of penetration, although massive and tenacious binding of spermatozoa to the plasmalemma was observed. Zona-free tubal eggs inseminated in parallel control experiments were penetrated. After GVB, penetration of zona-free oocytes occurred readily (Pl. 1, Fig. 5).

\section{PLATE 2}

Fig. 7. Transmission electron micrograph of a GV-intact oocyte exposed to capacitated spermatozoa for $9 \mathrm{~h}$ in the presence of Biggers' medium containing $100 \mu \mathrm{g} \mathrm{dbcAMP} / \mathrm{ml}$. The nuclear membrane (NM) containing a single large nucleolus is visible within the oocyte cytoplasm, as are numerous peripherally localized cortical granules. Several attached spermatozoa are also visible. $\times 4380$.

Fig. 8. Equatorial section of a GV-intact oocyte exposed to capacitated spermatozoa as in Fig. 7. Again, numerous cortical granules are apparent in the peripheral cytoplasm. Note that most attached spermatozoa retain intact acrosomes. $\times 6000$. Insets: Higher magnification of attached spermatozoon with (a) a reacted acrosome $(\times 24000)$ or (b) an intact acrosome $(\times 18200)$. 
When dibutyryl cyclic AMP (dbcAMP) was included to inhibit GVB and inseminations were conducted for up to $9 \mathrm{~h}$, all oocytes (55) remained at the GV-intact stage and none was penetrated. Control studies with zona-free tubal eggs indicated that dbcAMP did not have an adverse effect on penetration, as the mean number of spermatozoa/egg remained high in its presence (3.1 versus 3.6). After sperm exposure, four $G V$-intact oocytes were step-sectioned (3 incubated with dbcAMP, one without) and were examined at high resolution, but again no evidence for penetration was obtained (Pl. 2, Fig. 7). These oocytes were characterized by extensive uniformly distributed microvilli and contained 32.2 cortical granules/egg section compared with a mean value of 40.42 reported by us previously for unfertilized tubal eggs (Nicosia, Wolf \& Inoue, 1977). Many of the granules had not assumed their characteristic ectoplasmic location. Of the large number of spermatozoa recovered with these oocytes, only $31 \%(49 / 130)$ had reacted acrosomes (Pl. 2, Fig. 8). In contrast, nearly all spermatozoa (32/34) recovered with tubal eggs had undergone acrosome reactions.

When inseminations of GV-intact oocytes were conducted with ionophore-treated spermatozoa, penetration was confirmed by the presence of inner acrosomal membrane remnants in the ooplasm (Pl. 1, Fig. 6). Penetration of $60-100 \%$ of the oocytes was seen in 2 experiments conducted in Medium 2 without added dbcAMP. When this medium was supplemented with dbcAMP (3 experiments), penetration did not occur.

\section{Kinetics of sperm penetration}

The kinetics of sperm penetration into zona-free oocytes and tubal eggs were compared over a 240-min period. Freshly collected oocytes without visible GVs were selected for this purpose. When inseminated with $10^{5}$ spermatozoa $/ \mathrm{ml}, 100 \%$ of these oocytes were penetrated, and most were polyspermic $(80 \%)$. The penetration kinetics were virtually identical for maturing oocytes and tubal eggs, with an initial delay (approximately $30 \mathrm{~min}$ ) before penetration began, followed within $90 \mathrm{~min}$ by the attainment of a relatively stable plateau level of incorporation. The mean number of spermatozoa/egg was 3.2 and 3.5 for tubal eggs and follicular oocytes, respectively. Sperm viability is retained over these time courses (Wolf, 1978).

\section{Discussion}

Preovulatory maturation of mammalian oocytes, as triggered by the mid-cycle gonadotrophin surge, involves reception of the pituitary message and its subsequent transmission through the intrafollicular environment to the oocyte. Co-ordinated changes in surface membrane and cytoplasmic components of the oocyte then culminate in nuclear activation, GVB and the progression of meiosis to metaphase II. Direct evidence for cytoplasmic control of GVB in the mouse is available (Balakier \& Czolowska, 1977). The relationship between these processes, as they occur in vivo, and the spontaneous meiotic maturation that results in vitro in oocytes removed from antral follicles, however, remains an enigma.

These responses may reflect the differential role of follicular cells. Cumulus cells are almost certainly involved in vivo during gonadotrophin-induced maturation, where disruption of their electrical coupling (gap junctions) with the oocyte may trigger maturation resumption (Anderson \& Albertini, 1976). In the pig, granulosa cells are associated with the production of a low molecular weight peptide which maintains the oocyte in its arrested state (for review, Channing \& Tsafriri, 1977). The presence of cumulus cells is not critical in the spontaneous maturation of isolated oocytes (Cross, 1973; this study), although some evidence suggests that cumulus cell removal decreases maturation rates (Cross \& Brinster, 1970). We have extended these observations to show that the zona pellucida is also dispensable during maturation in vitro, since zona-free oocytes matured with a frequency and rate similar to that reported for intact 
oocytes (Donahue, 1968; Stern \& Wassarman, 1974). The zona is, however, critical to embryo survival and transport (Modlinski, 1970), and it has been associated with the exclusion of supernumerary spermatozoa in several species (Austin, 1965).

Our sperm penetration results corroborate previous findings (Iwamatsu \& Chang, 1972) in the mouse. Before GVB, incorporation of capacitated spermatozoa does not normally occur, while after GVB, the primary oocyte fuses with a spermatozoon and its cytoplasm is capable of decondensing the incorporated sperm head. The present work also indicates that zona penetration is not the limiting factor in the inability of GV-intact oocytes to fuse with spermatozoa. Usui \& Yanagimachi (1976) have documented sperm incorporation in GV-intact oocytes of the hamster, and in the present study inseminations in the presence of ionophore led occasionally to penetration. In neither study was sperm head decondensation associated with penetration.

The restricted ability of GV-intact oocytes to fuse with capacitated spermatozoa is presumably reflected in surface events. Thus, while large numbers of spermatozoa attach to these oocytes, critical binding sites may be lacking. Another possibility is that the oocyte does not induce acrosome reactions in the normal complement of attached spermatozoa. While this role is not usually afforded the oocyte, several relevant observations can be considered: (1) spermatozoa must undergo an acrosome reaction before they fuse with zona-free tubal eggs (Yanagimachi \& Noda, 1970; Wolf, Inoue \& Stark, 1976); (2) a lower percentage of the spermatozoa attached to GV-intact oocytes, compared with tubal eggs, have reacted acrosomes; and (3) penetration of GV-intact oocytes was seen only in the presence of an agent (ionophore) which has acrosome reaction-inducing activity (Talbot, Summer, Hylander, Keough \& Franklin, 1976). We have suggested previously that premature cortical granule release may provide a mechanism for sperm-egg communication before penetration (Nicosia et al., 1977).

The kinetics of sperm incorporation indicate that the primary oocyte is capable of a plasmalemma block to penetration which, in view of the probable incomplete status of cortical granule complements (Szollosi, 1967; Zamboni, 1970), suggests that these structures are not involved. Cortical granules apparently do not play a role in the plasmalemma block of mouse tubal eggs, since zona-free eggs remain penetrable even after premature cortical granule loss (Wolf \& Hamada, 1978). Evidence has been presented recently supporting the existence of an electricallymediated block at the surface of marine invertebrate eggs. This block is transient, occurs before cortical granule exocytosis and may be a feature of mammalian eggs (Jaffe, 1976; GouldSomero \& Jaffe, 1977).

We thank Dr Santo Nicosia, Ms Janice Sowinski and Ms Barbara J. Arner for their capable assistance in the high resolution analyses and Ms Patricia Park for secretarial assistance. This work was supported by USPHS grants HD-07635 and HD-06274-Project 2 and the E.M. Core.

\section{References}

Anderson, E, \& Albertini, D, (1976) Gap junctions between the oocyte and companion follicle cells in mammalian ovary. J. Cell Biol. 71, 680-686.

Austin, C.R. (1965) Fertilization. Prentice-Hall, Englewood Cliffs, New Jersey.

Balakier, H. \& Czolowska, R. (1977) Cytoplasmic control of nuclear maturation in mouse oocytes. Expl Cell Res. 110, 466-469.

Barros, C. \& Munoz, G. (1973) Sperm-egg interaction in immature hamster oocytes. J. exp. Zool. 186, 73-78.

Biggers, J.D. (1971) New observations on the nutrition of the mammalian oocyte and the pre-implantation embryo. In The Biology of the Blastocyst, pp. 319-
327. Ed. R. J. Blandau. University of Chicago Press, Chicago.

Biggers, J.D., Whittingham, D.G. \& Donahue, R.P. (1967) The pattern of energy metabolism in the mouse oocyte and zygote. Proc. natn. Acad. Sci. U.S.A. 58, 560-567.

Channing, C.P. \& Tsafriri, A. (1977) Mechanism of action of luteinizing hormone and follicle stimulating hormone on the ovary in vitro. Metabolism 26, 413468.

Cho, W.K., Stern, S. \& Biggers, J.D. (1974) Inhibitory effect of dibutyryl cAMP on mouse oocyte maturation in vitro. J. exp. Zool. 187, 383-386. 
Cross, P.C. (1973) The role of cumulus cells and serum in mouse oocyte maturation in vitro. J. Reprod. Fert. 34, 241-245.

Cross, P.C. \& Brinster, R.L. (1970) In vitro development of mouse oocytes. Biol. Reprod. 3, 298-307.

Donahue, R.P. (1968) Maturation of the mouse oocyte in vitro. I. Sequence and timing of nuclear progression. J. exp. Zool. 169, 237-250.

Donahue, R.P. \& Stern, S. (1968) Follicular cell support of oocyte maturation: production of pyruvate in vitro. $J$. Reprod. Fert. 17, 395-398.

Gould-Somero, M. \& Jaffe, L.A. (1977) Electrically mediated fast polyspermy block in eggs of the marine worm Urechis. J. Cell Biol. 75, 37a.

Iwamatsu, T. \& Chang, M.C. (1972) Sperm penetration in vitro of mouse oocytes at various times during maturation. J. Reprod. Fert. 31, 237-247.

Jaffe, L.A. (1976) Fast block to polyspermy in sea urchin eggs is electrically mediated. Nature, Lond. 261, 68-71.

Luft, J.H. (1961) Improvements in epoxy resin embedding methods. J. Biophys. Biochem. Cytol. 9, 409414.

Modlinski, J.A. (1970) The role of zona pellucida in the development of mouse eggs in vivo. J. Embryol. exp. Morph. 23, 539-547.

Mukherjee, A.B. \& Cohen, M.M. (1970) Development of normal mice by in vitro fertilization. Nature, Lond. 228, 472 .

Nicosia, S.V., Wolf, D.P. \& Inoue, M. (1977) Cortical granule distribution and cell surface characteristics in mouse ova. Devl. Biol. 57, 56-74.

Reynolds, E.S. (1963) The use of lead citrate at high pH as an electron-opaque stain in electron microscopy. J. Cell Biol. 17, 208-212.

Stern, S. \& Wassarman, P.M. (1974) Meiotic maturation of the mammalian oocyte in vitro: effect of dibutyryl cyclic AMP on protein synthesis. J. exp. Zool. 189, $275-281$.

Szollosi, D. (1967) Development of cortical granules and the cortical reaction in rat and hamster eggs. Anat. Rec. 159, 431-446.

Talbot, P., Summer, R.G., Hylander, B.L., Keough, E.M. $\&$ Franklin, L.E. (1976) The role of calcium in acrosome reaction: an analysis using ionophore A23187. J. exp. Zool. 198, 383-392.

Thibault, C. (1977) Are follicular maturation and oocyte maturation independent processes? J. Reprod. Fert. $51,1-15$.

Usui, N. \& Yanagimachi, R. (1976) Behavior of hamster sperm nuclei incorporated into eggs at various stages of maturation, fertilization and early development. $J$. Ultrastruct. Res. 57, 276-288.

Wolf, D.P. (1978) The block to sperm penetration in zona-free mouse eggs inseminated in vitro. Devl. Biol. 64, 1-10.

Wolf, D.P. \& Hamada, M. (1978) The block to polyspermy in zona-free mouse eggs. Fedn Proc. Fedn Am. Socs exp. Biol. 37, 380, Abstr.

Wolf, D.P. \& Inoue, M. (1976) Sperm concentration dependency in the fertilization and zonae sperm binding properties of mouse eggs inseminated in vitro. J. exp. Zool. 196, 27-38.

Wolf, D.P., Inoue, M. \& Stark, R.A. (1976) Penetration of zona-free mouse eggs. Biol. Reprod. 15, 213-221.

Yanagimachi, R. \& Noda, Y.D. (1970) Physiological changes in the postnuclear cap region of mammalian spermatozoa: a necessary preliminary in the membrane fusion between sperm and egg cells. J. Uitrastruct. Res. 31, 486-493.

Zamboni, L. (1970) Comparative studies on the ultrastructure of mammalian oocytes. In Oogenesis, pp. 5-45. Eds. J. D. Biggers \& A. W. Schuetz. University Park Press, Baltimore, Maryland.

Received 4 December 1978 